$$
\underset{\text { Final }}{D O E} / B C / 14896 \cdots 17
$$

\title{
GEOLOGICAL AND PETROPHYSICAL CHARACTERIZATION OF THE FERRON SANDSTONE FOR 3-D SIMULATION OF A FLUVIAL-DELTAIC RESERVOIR (Contract No. DE-AC22-93BC14896)
}

\section{TECHNICAL PROGRESS REPORT}

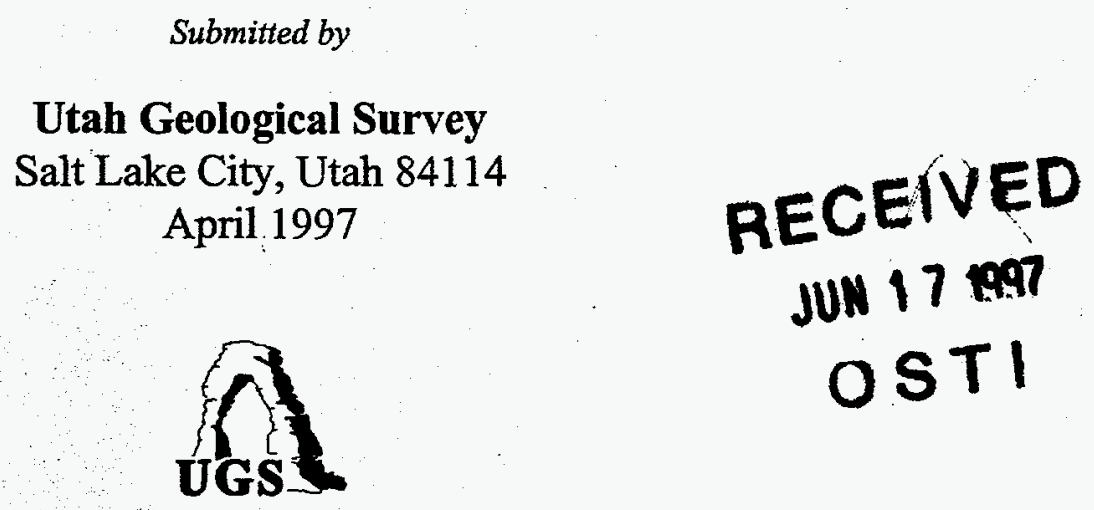

Contract Date: September 29, 1993

Anticipated Completion Date: August 28, 1997

Government Award (fiscal year): $\$ 61,648$

Program Manager: Thomas C. Chidsey, Jr.

Principal Investigator: M. Lee Allison

Contracting Officer's Representative

Robert Lemmon

U.S. Department of Energy

National Petroleum Technology Office

P.O. Box 1398

Bartlesville, OK 74005

Reporting Period: January 1 - March 31, 1997

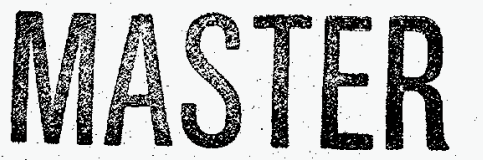

US/DOE Patent Clearance is not required prior to the publication of this document.

DISTRIBUTION OF THIS. DOCUMENT IS UNLIMITED 


\section{DISCLAMIER}

Portions of this document may be illegible in electronic image products. Images are produced from the best available original document. 
Report Title:

GEOLOGY AND PETROPHYSICAL CHARACTERIZATION OF THE

FERRON SANDSTONE FOR 3-D SIMULATION OF A

FLUVIAL-DELTAIC RESERVOIR

Report Type:

QUARTERLY

Reporting Period Start Date:01/01/1997 End Date: 03/31/1997

Principal Author(s): Thomas C. Chidsey, Jr.

Paul B. Andserson

Craig B. Forster

Steve H. Snelgrove

Ann Mattson

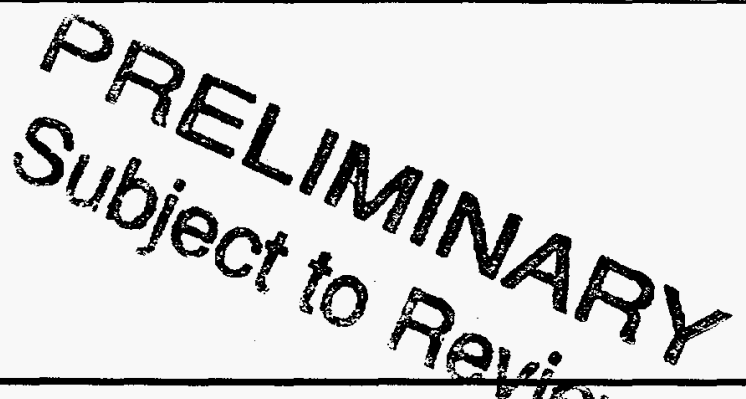

Report Issue Date: 05/20/1997

DOE Award No.: DE- AC22 -93BC14856

Submitting

Organization(s)

Name \& Address
Utah Geological Survey

PO Box 146100

Salt Lake City, UT 84114-6100
(1)

(2)

Anderson Geological Consulting

807 East South Temple, Suite 101

Salt Lake City, UT 84102

University of Utah
Salt Lake City, UT 84112

University of Utah
Salt Lake City, UT 84112

Energy \& Geoscience Institute

1515 E. Mineral Square, Suite142

Dept. of Geology \& Geophysics

608 W. Browning Bldg.

University of Utah

Salt Lake City, UT 84112 


\section{DISCLAIMER}

This report was prepared as an account of work sponsored by an agency of the United States Government. Neither the United States Government nor any agency thereof, nor any of their employees, makes any warranty, express or implied, or assumes any legal liability or responsibility for the accuracy, completeness, or usefulness of any information, apparatus, product, or process disclosed, or represents that its use would not infringe privately owned rights. Reference herein to any specific commercial product, process, or service by trade name, trademark, manufacturer, or otherwise does not necessarily constitute or imply its endorsement, recommendation, or favoring by the United States Government or any agency thereof. The views and opinions of authors expressed herein do not necessarily state or reflect those of the United States Government or any agency thereof. 


\section{GEOLOGICAL AND PETROPHYSICAL CHARACTERIZATION \\ OF THE FERRON SANDSTONE FOR 3-D SIMULATION OF A FLUVIAL-DELTAIC RESERVOIR}

(Contract No. DE-AC22-93BC14896)

Utah Geological Survey (UGS), Salt Lake City, Utah 84114

Submitted: May 1997

Contract Date: September 29, 1993

Anticipated Completion Date: August 28, 1997

Government Award (fiscal year): $\$ 61,648$

Principal Investigator: M. Lee Allison, UGS

Program Manager: Thomas C. Chidsey, Jr., UGS

Contracting Officer's Representative: Robert Lemmon, National Petroleum Technology Office, Bartlesville, Oklahoma

Reporting Period: January 1 - March 31, 1997

\section{Objective}

The objective of this project is to develop a comprehensive, interdisciplinary, and quantitative characterization of a fluvial-deltaic reservoir which will allow realistic inter-well and reservoir-scale modeling to be constructed for improved oil-field development in similar reservoirs world-wide. The geological and petrophysical properties of the Cretaceous Ferron Sandstone in east-central Utah will be quantitatively determined. Both new and existing data will be integrated into a three-dimensional representation of spatial variations in porosity, storativity, and tensorial rock permeability at a scale appropriate for inter-well to regional-scale reservoir simulation. Results could improve reservoir management through proper infill and extension drilling strategies, reduction of economic risks, increased recovery from existing oil fields, and more reliable reserve calculations. Transfer of the project results to the petroleum industry is an integral component of the project. 


\section{Summary of Technical Progress}

Four activities continued this quarter as part of the geological and petrophysical characterization of the fluvial-deltaic Ferron Sandstone in the Ivie Creek case-study area (Fig. 1): (1) regional stratigraphic interpretation, (2) case-study evaluation, (3) reservoir modeling, and (4) technology transfer.

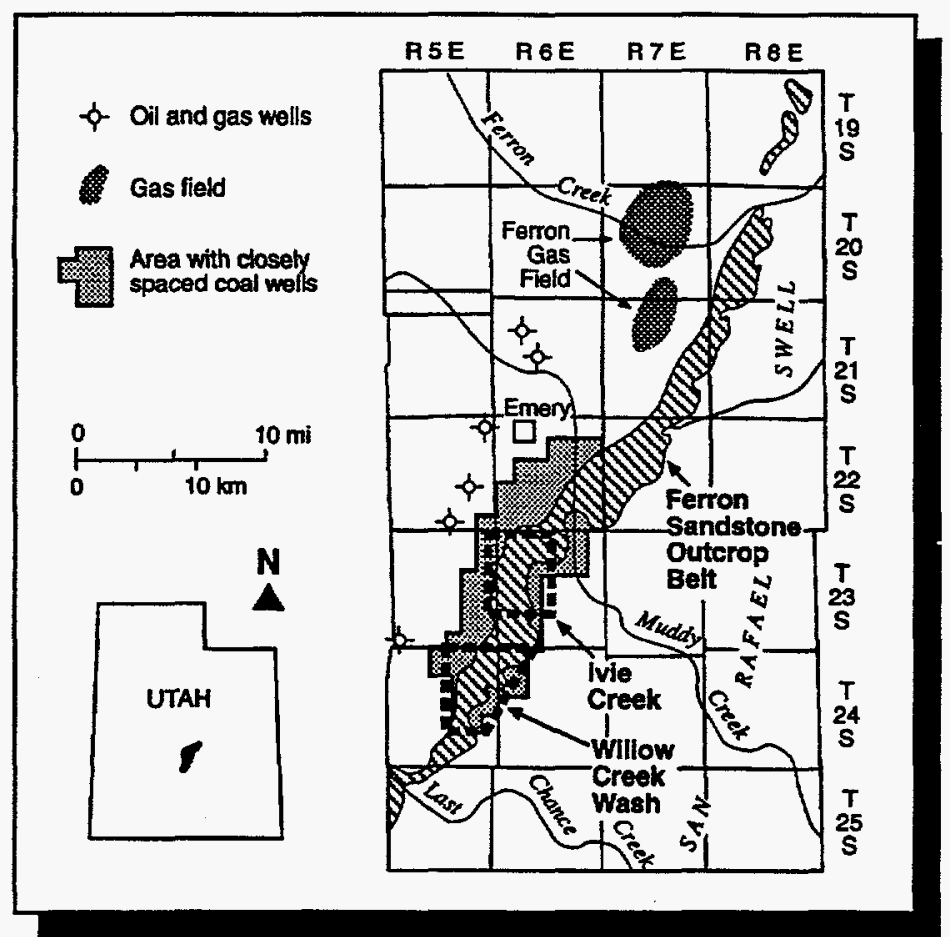

Fig. 1. Location map of the Ferron Sandstone outcrop belt (cross-hatched), showing case-study areas (outlined in heavy dashed lines).

\section{Regional Stratigraphic Interpretation}

The Utah Geological Survey (UGS) continued to interpret photomosaics of the Ferron Sandstone outcrop belt (Fig. 1). Photomosaic interpretation uses observations from the 1994 and 1995 field seasons. Each photomosaic is being annotated with following: flooding surfaces (transgressive surfaces of erosion), possible parasequence boundaries (surfaces which may be a flooding surface, but for which there is not clear evidence of transgression), base of channels, depositional tops of shoreline and bay-fill units, significant bedding surfaces of shoreline units, lateral accretion in tidal inlet and fluvial channel deposits, and bedding surfaces in slump features. A scale bar is included on the photomosaics based on the measurements made in the field on location points which are visible in the photographs. Field-based topographic map tie points are also included as well as match points for adjacent photomosaics. 
When completed, these photomosaics will be used for correlation, for development of cross sections, and for placement of the case-study areas into the regional setting. The photomosaics will be available on compact discs to researchers.

\section{Case-Study Evaluation}

The case-study evaluation work during the quarter included: (1) construction of paleogeographic maps in the Willow Springs Wash case-study area, (2) interpretation of photomosaics and construction of stratigraphic cross sections in the Ivie Creek case-study area, and (3) geostatistical analysis of permeability controls.

Outcrop-based paleogeographic maps were constructed for the various time steps of parasequences in the Ferron Sandstone No. 1 (Kf-1) parasequence set. For example, during the first time step of deposition of the Kf-1-Indian Canyon-c parasequence, the shoreline trend was northwest-southeast (Fig. 2). A tidal inlet and associated ebb-tidal delta developed in the southwestern part of the case-study area. Measurements of paleocurrents within the upper shoreface/ebb-tidal delta facies show northeast-directed flow.

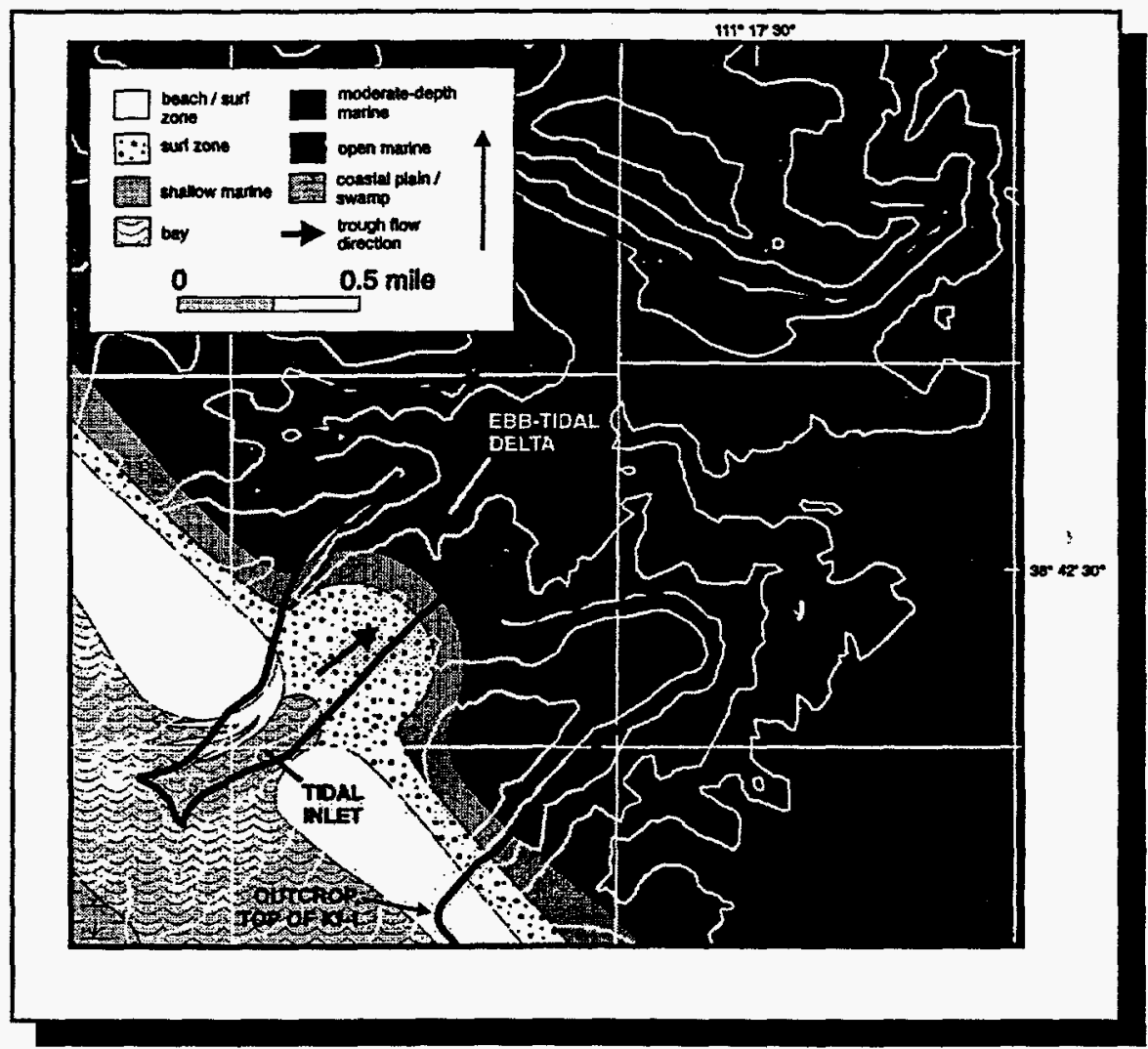

Fig. 2. Paleogeographic interpretation of the Willow Springs Wash case-study area during deposition of the first step of the Kf-1-Indian Canyon-c parasequence. The ebb-tidal delta is in the SW1/4 section 24, T. 24 S., R. 5 E., of the Salt Lake Base Line. 
Photomosaics from the Ivie Creek case-study area are being annotated with the same information as the regional photomosaics. Five cross sections were constructed to tie into the regional picture and for use in the three-dimensional reservoir modeling effort. These cross sections display: (1) parasequence and parasequence set boundaries, (2) measured sections which include lithology, sedimentary structures, and ichnofossils, and (3) correlations through project drill holes.

From data collected in the Ivie Creek case-study area, a statistical comparison of grain size (Fig. 3A) and permeability (Fig. 3B) vs. facies was conducted. This comparison indicates grain size is not the only control on permeability. In general the fluvial-dominated facies of the Kf-1-Ivie Creek-a (Kf-1-Iv-a) parasequence have lower permeability values than wave-modified facies of the Ferron No. 2 (Kf-2) parasequence set in Ivie Creek that exhibit similar grain-size distributions. For example, clinoform proximal facies of the $\mathrm{Kf}-1$-Iv-a have a similar grain-size distribution as upper shoreface facies of the $\mathrm{Kf}-2$. However, the permeability distribution for the clinoform proximal facies is much lower and is comparable to the middle shoreface facies of the $\mathrm{Kf}-2$. Other factors that probably influence permeability distributions are grain sorting, mineralogical composition, and rock type.

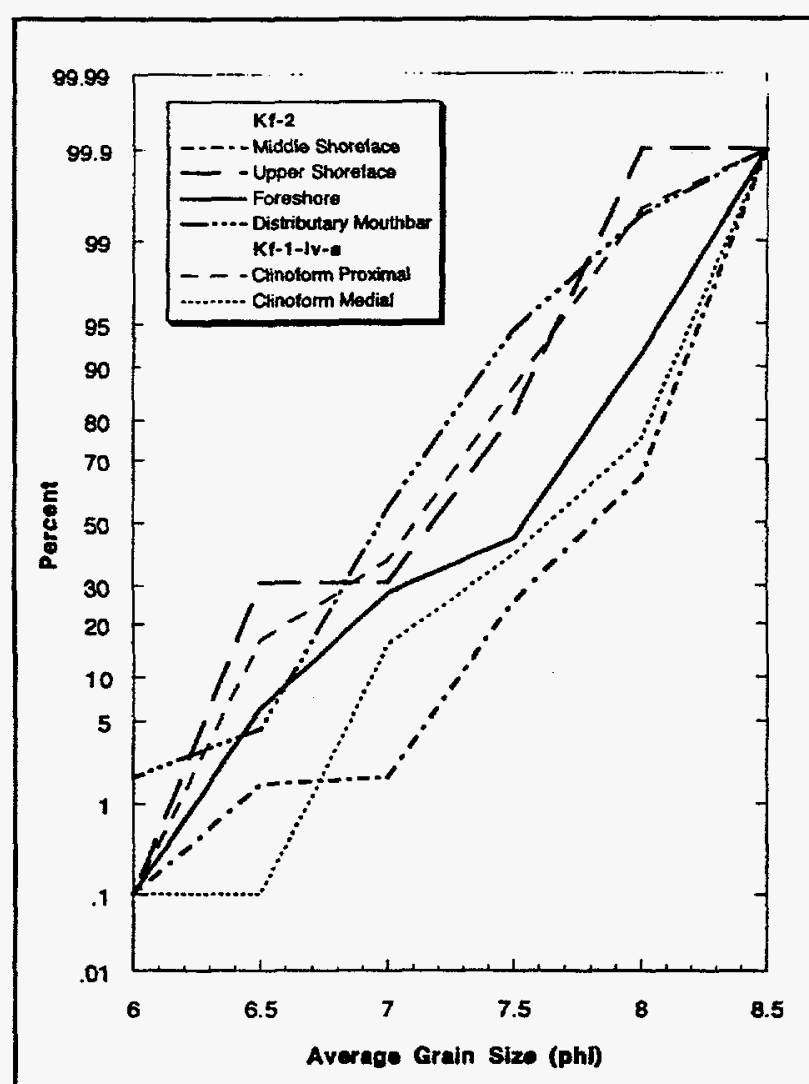

(A)

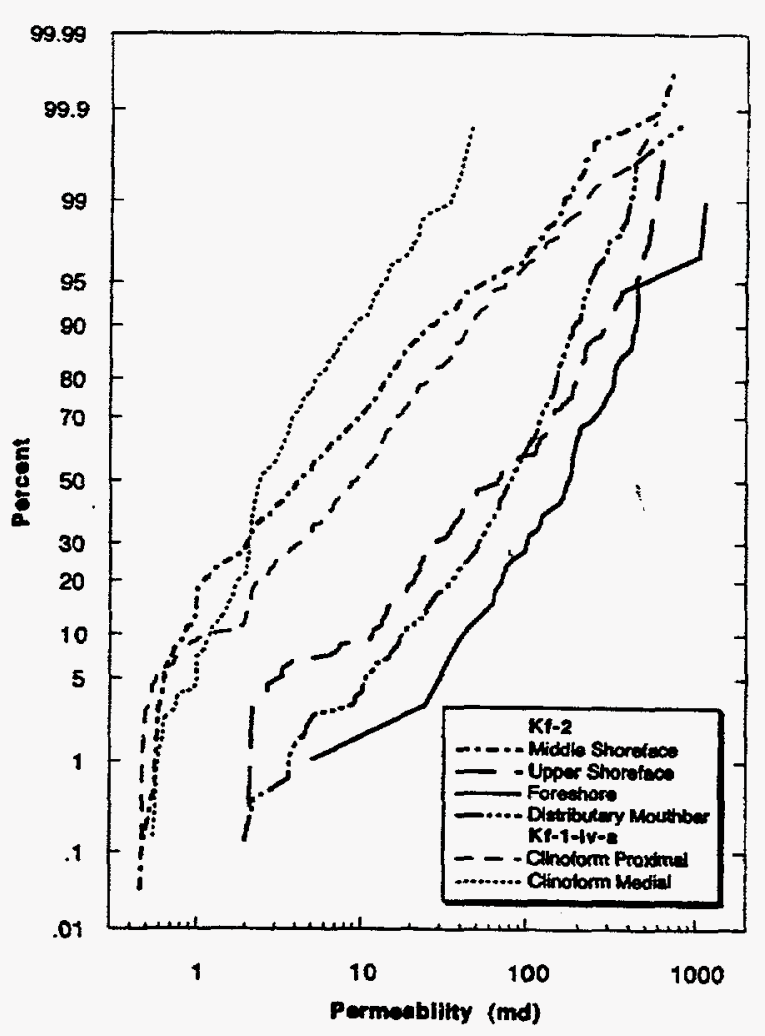

(B)

Fig. 3. Cumulative percent plots of (A) grain size, and (B) permeability vs. potential reservoir facies of the $\mathrm{Kf}-2$ parasequence set and the $\mathrm{Kf}-1-\mathrm{Iv}$-a parasequence in the Ivie Creek case-study area. 


\section{Reservoir Modeling}

The primary goal of the three-dimensional simulation task is to explore and illustrate the impact of upscaled, clinoform-related permeability structures on secondary oil production. The first phase of three-dimensional simulations are complete and the second and final simulation phase is about to begin. Detailed, layered, and homogeneous permeability/porosity structures were modeled within the Kf-1-Iv-a parasequence of the detailed Ivie Creek case-study volume in the first phase of simulations. In each case isotropic permeability tensors are assumed.

The detailed structure is derived from the detailed three-dimensional facies model developed by the geological team within the Kf-1-Iv-a facies. Absolute permeabilities are assigned to each facies as the geometric mean of values estimated from the field studies. Porosity values are computed from an empirical relationship between permeability and porosity that was derived from the laboratory tests performed on core plugs collected from outcrop. Figure 4 shows the distribution of absolute permeability assigned in the detailed case.

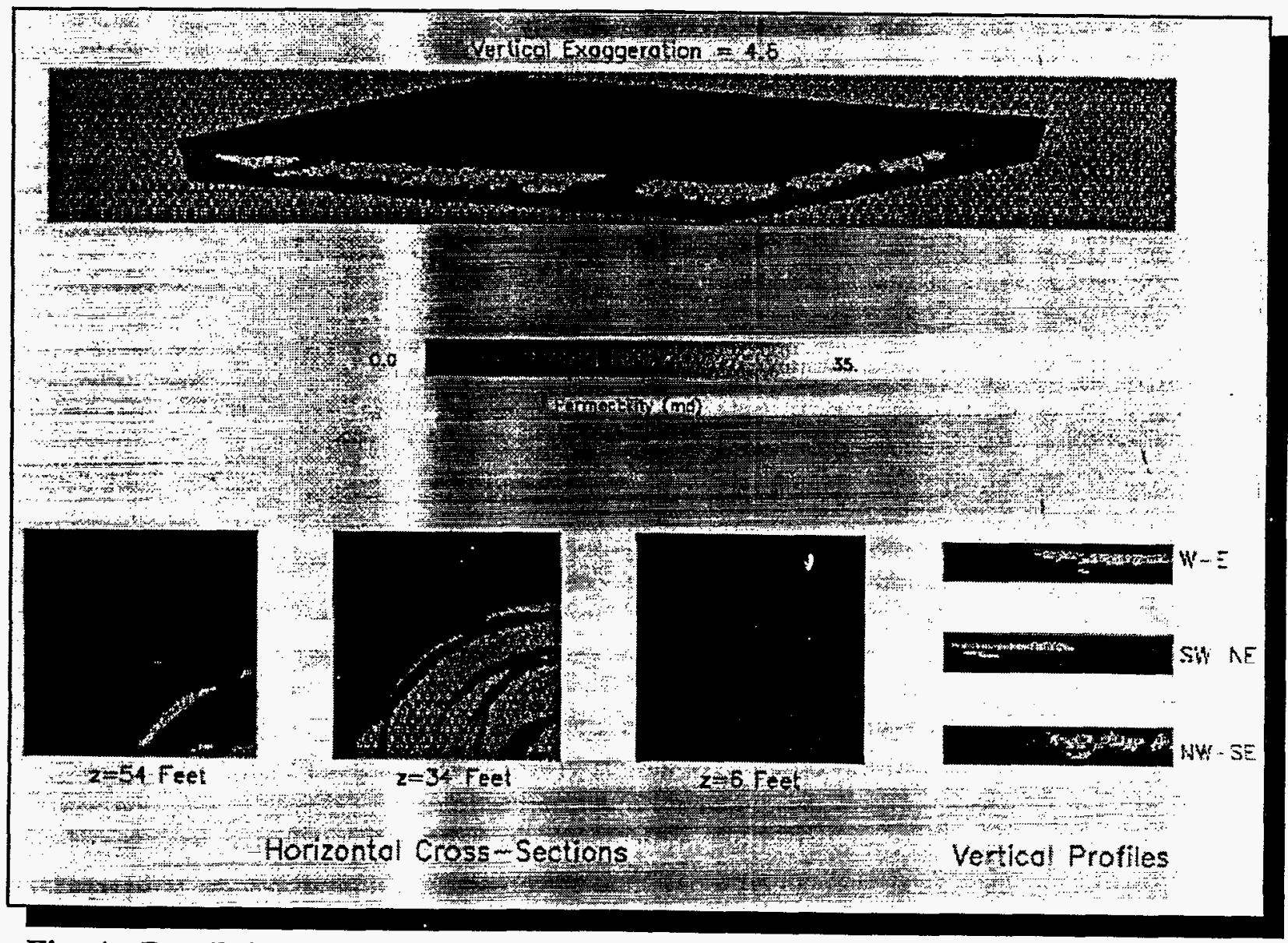

Fig. 4. Detailed permeability distribution assigned in the detailed case for the Kf-1-Iv-a parasequence. 
The layered structure (Fig. 5) is a simplified version of the detailed structure constructed using vertical facies distributions extracted from the detailed model at each of the four corners of the model domain. Permeability and porosity of the layered structure were assigned in the same way as those assigned in the detailed model.

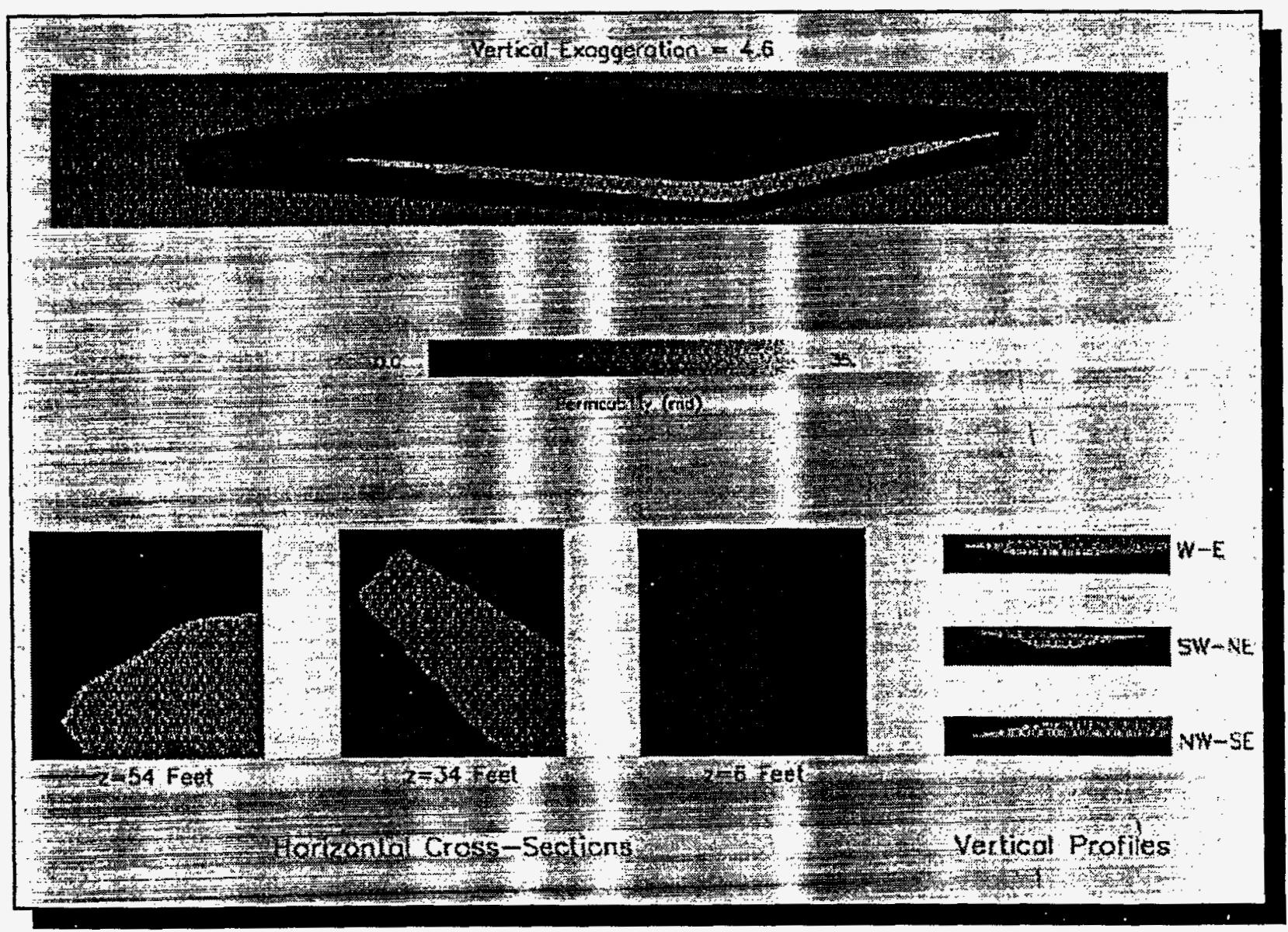

Fig. 5. Layered permeability distribution for the Kf-1-Iv-a parasequence simplified from the detailed model.

The homogeneous structure is the simplest permeability structure with the absolute permeability computed from the geometric mean of values associated with each facies. The porosity is computed from the same empirical relationship used in the detailed and layered cases.

Relative permeabilities are assigned in the model using relationships developed from laboratory test data reported for samples of Ferron and Berea Sandstone. ${ }^{1}$ Capillary pressures were obtained from the standard water-wet relationships. Fluid properties are defined to be consistent with an initial reservoir fluid pressure of 5000 pounds per square inch absolute (psia). Wherever possible, fluid properties are specified to be the same as those used to conduct the black oil simulations performed for the Comparative Solution Project. ${ }^{2}$ A two-phase oil/water system is assumed, thus the gas phase is not considered.

Each run was made with the TETRAD three-dimensional simulator using a model grid with dimensions $2000 \mathrm{ft}$ by $2000 \mathrm{ft}$ in plan view and $60 \mathrm{ft}$ thick. The domain contains 150,000 rectilinear 
grid blocks each $20 \mathrm{ft}$ by $2 \mathrm{ft}$ in plan view and $4 \mathrm{ft}$ thick. Thus, there are 15 layers each with a grid of 100 by 100 blocks. Estimated original oil in place differs for each model domain: 2.99 million barrels of oil (MMBO) in the detailed case, $2.67 \mathrm{MMBO}$ in the layered case, and 2.07 $\mathrm{MMBO}$ in the homogeneous case.

In order to minimize computer time the primary production stage was bypassed to make all runs in a waterflood mode starting at an initial uniform oil saturation of 0.50 . Four fully-screened production wells were placed at each corner of the model domain with one fully-screened well in the middle of the model.

Sample simulation results are shown as plots of oil saturation at five years after the start of production for both the detailed (Fig. 6) and layered (Fig. 7) models. The simulation results are consistent with expectations given the assigned input parameters. Preliminary analysis of the results indicates that the homogeneous case requires substantially less water injection to produce a specified volume of oil, however, an extended production time is required to sweep the reservoir. Although the results obtained for the layered and detailed cases differ markedly from those of the homogeneous case, they are similar to one another. After 20 years of production the layered and detailed models yield about $30 \%$ of the original oil in place with the layered model providing somewhat better recovery. The detailed model, however, requires slightly less water injection to produce the same amount of oil that is produced in the layered model at a specified point in time.

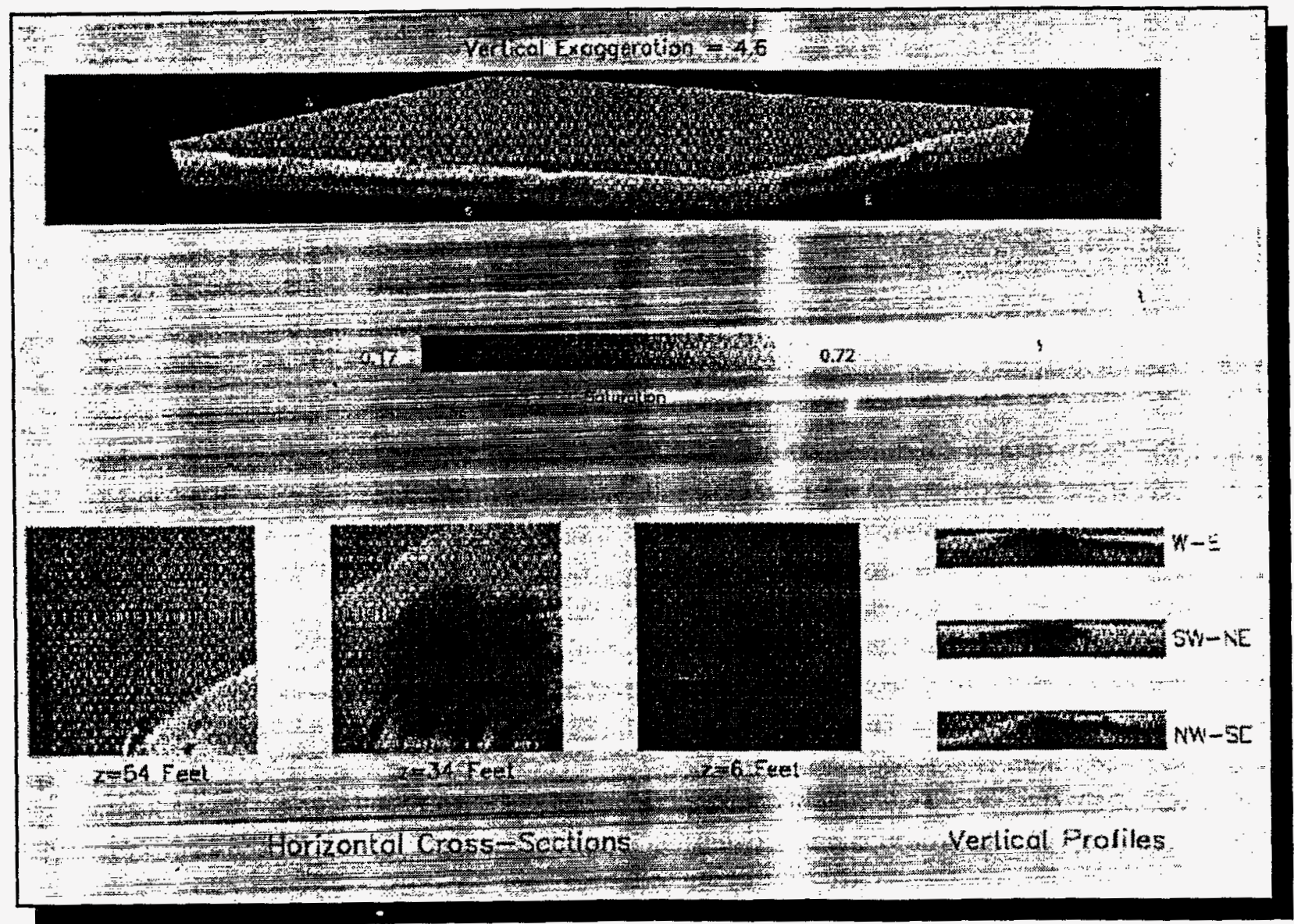

Fig. 6. Sample plot of oil saturation at five years after the start of production from simulation of the detailed model. 


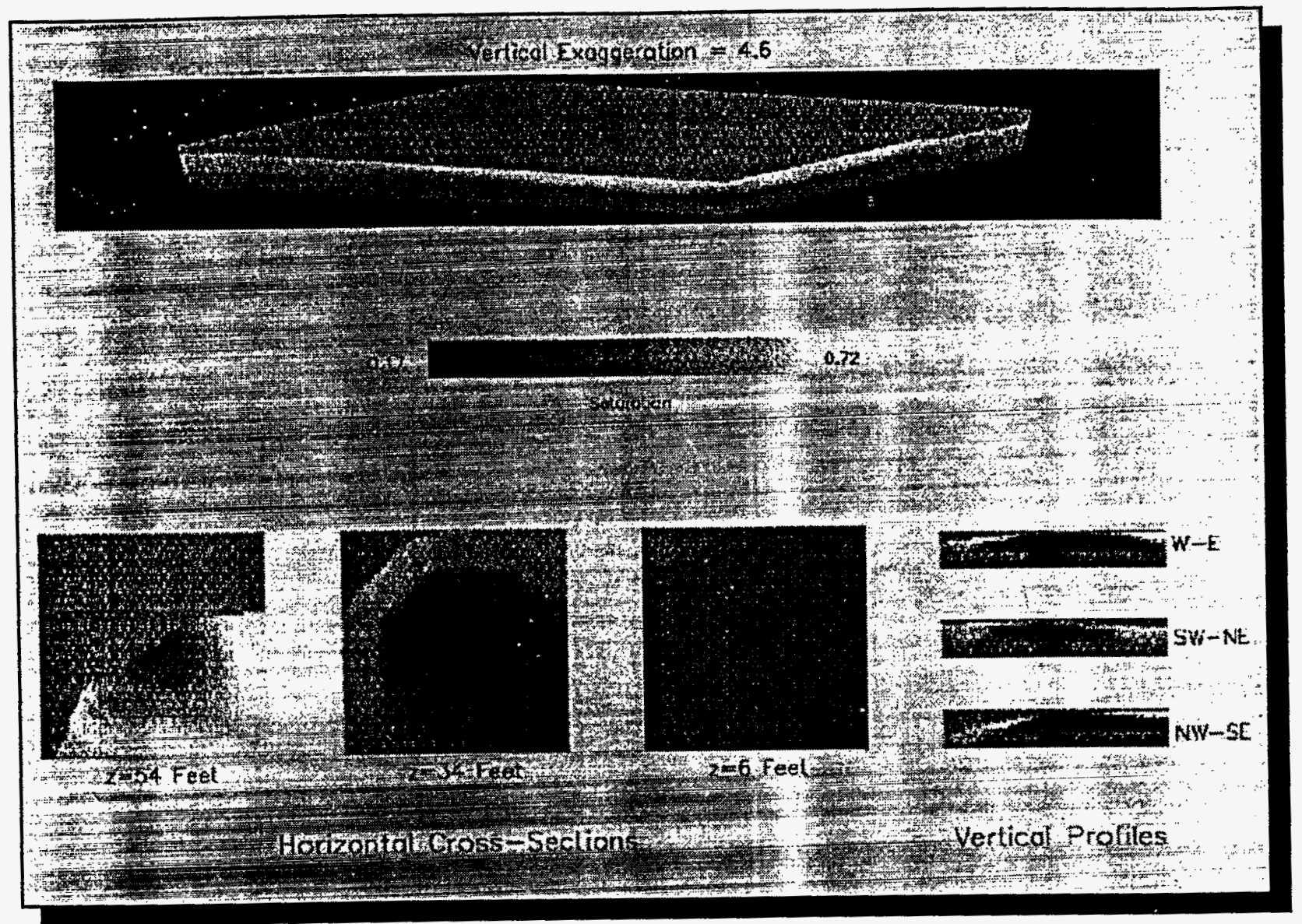

Fig. 7. Sample plot of oil saturation at five years after the start of production from simulation of the layered model.

\section{Technology Transfer}

The UGS and its partners continued to prepare presentations of the final results of the project to both academia and industry. During the quarter, road logs were prepared covering the regional stratigraphy and case-study areas for field trips to be conducted during the 1997 Geological Society of America (GSA) and 1998 American Association of Petroleum Geologists (AAPG) annual national meetings. The field trip road logs and Ferron interpretations, titled Fluvial-Deltaic Sedimentation and Stratigraphy of the Ferron Sandstone, will be published in the fall of 1997 in a two-volume GSA guidebook. A short course presenting reservoir modeling and simulation results will also be offered during the AAPG meeting. The meetings will be held in Salt Lake City, Utah, October 1922, 1997 (GSA) and May 17-20, 1998 (AAPG). The field trip and short course presented at the AAPG meeting will be sponsored by the UGS, National Petroleum Technology Office - DOE, Mobil Technology Company, and Amoco Production Company. 